\title{
A Formação em Psicologia Após 50 Anos do Primeiro Currículo Nacional da Psicologia - Alguns Desafios Atuais
}

Training In Psychology 50 Years After The First National Curriculum Of Psychology - Some Current Challenges

Formación En Psicología 50 Años Después Del Primer Plan De Estudios Nacional En Psicología - Algunos Desafios Actuales
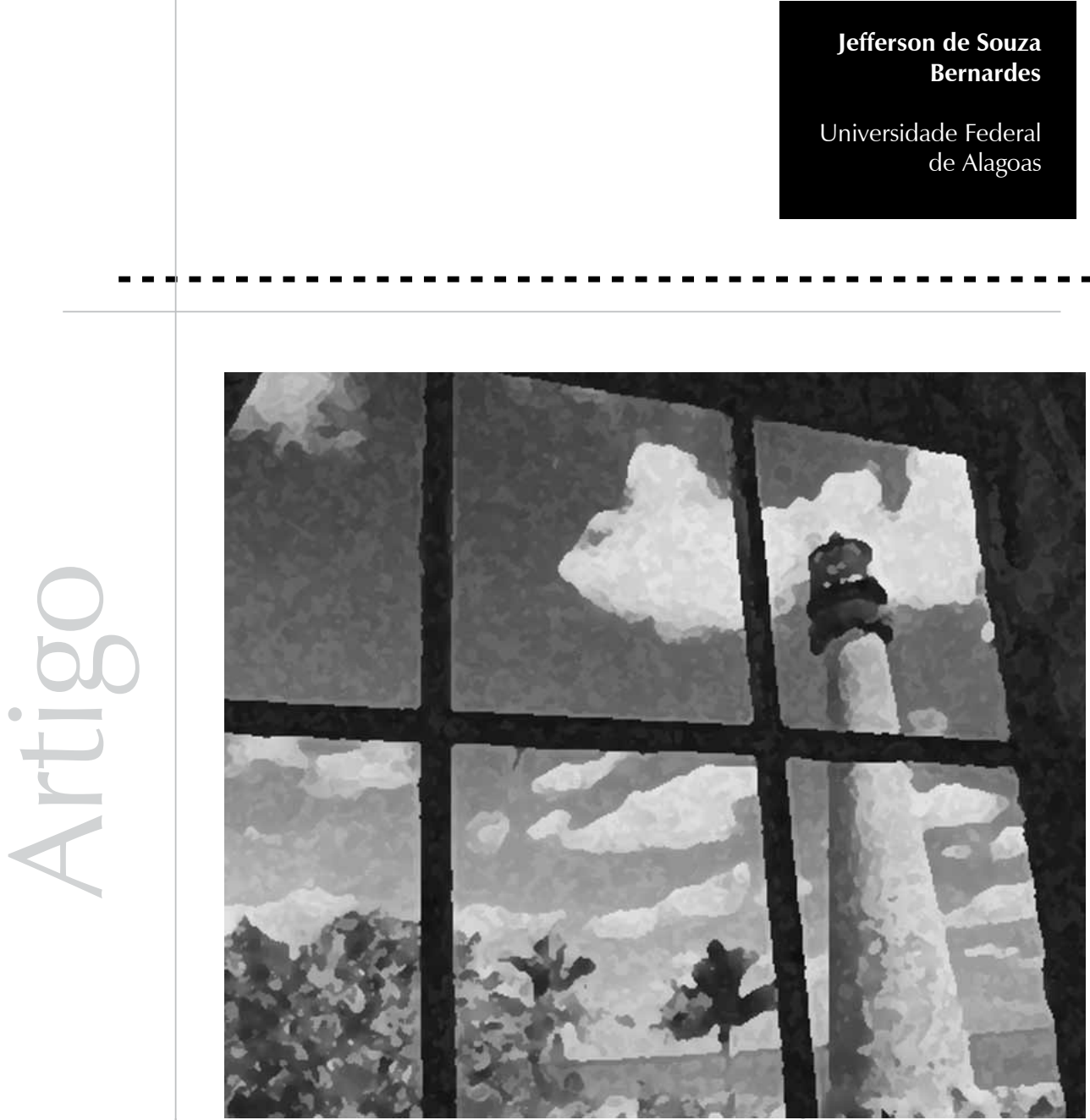
Resumo: Atualmente, muitos cursos estão a pleno vapor tentando terminar a implantação ou avaliando seus currículos, conforme determinado pelas novas Diretrizes Curriculares, homologadas pelo Ministério da Educação, em 2004. A construção das Diretrizes Curriculares marca um processo histórico importante para a Psicologia brasileira, pois foram produzidas a partir de debates, de relações de poder e de intensas negociações entre diversos atores/autores e instituições. Como todo processo histórico e coletivo, foi marcado por avanços e retrocessos. A partir da análise das novas Diretrizes Curriculares, observações e conversas com professores e estudantes de diversos cursos no País, problematizo dois conceitos das Diretrizes Curriculares em Psicologia: competências/habilidades e ênfases curriculares. Argumento que as Diretrizes Curriculares são dispositivos tecnológicos produzidos a partir de certa racionalidade prática, que caracterizam formas específicas de governo. Proponho ressignificar tais conceitos perspectivando uma formação em Psicologia orientada para um perfil generalista, vinculado aos contextos locais de produção de práticas sociais/profissionais, ampliando o conceito de competências para a competência linguística, originária da etnometodologia, e para a competência ética. Temos o que celebrar nestes 50 anos da regulamentação da profissão e do primeiro currículo nacional para os cursos de Psicologia, entretanto, no que diz respeito à formação, talvez não tanto quanto se gostaria.

Palavras-chave: Formação do psicólogo. Currículo. Ensino da Psicologia. Diálogo. Competência. Ensino superior.

\begin{abstract}
Nowadays, many courses are in full development, trying to finish the implantation or evaluating their curricula, as determined by the new Curriculum Guidelines, which were approved by the Ministry of Education in 2004. The elaboration of the Curriculum Guidelines marks an important and historical process to the Brazilian psychology. Those guidelines had been produced by debates, involved power relations and intense negotiations among different actors/authors and institutions. This process, like every historic and collective process, was marked by advances and setbacks. This work explores, by analysis of the new Curriculum Guidelines, observations and conversations with teachers and students from various courses in the country, as well as two concepts of Curriculum Guidelines in psychology: skills/abilities and the curricular emphases. By my argument, the technological devices of the curriculum are produced by certain practical rationality, with specific forms of government. I propose to reframe these concepts which provide training in psychology oriented to a generalist profile, linked to local contexts of production of social professional practices, expanding the concept of competence to language competence, which is originated in ethnomethodology, and ethical competence. We have to celebrate these 50 years of the professional regulation and the first national curriculum for courses in psychology. However, about the formation, perhaps we don't have much to celebrate.
\end{abstract}

Keywords: Psychologist education. Curriculum. Psychology Education. Dialogue. Competence. Higher education.

Resumen: Actualmente, muchos cursos están a pleno vapor tentando terminar la implantación o evaluando sus currículos, conforme determinado por las nuevas Directrices Curriculares, homologadas por el Ministerio de la Educación, en 2004. La construcción de las Directrices Curriculares marca un proceso histórico importante para la Psicología brasileña, pues fueron producidas a partir de debates, de relaciones de poder y de intensas negociaciones entre diversos actores/autores e instituciones. Como todo proceso histórico y colectivo, fue marcado por avances y retrocesos. A partir del análisis de las nuevas Directrices Curriculares, observaciones y conversaciones con profesores y estudiantes de diversos cursos en el País, problematizo dos conceptos de las Directrices Curriculares en Psicología: competencias/habilidades y énfasis curriculares. Argumento que las Directrices Curriculares son dispositivos tecnológicos producidos a partir de cierta racionalidad práctica, que caracterizan formas específicas de gobierno. Propongo re-significar tales conceptos dando perspectiva de una formación en Psicología orientada para un perfil generalista, vinculado a los contextos locales de producción de prácticas sociales/profesionales, ampliando el concepto de competencias para la competencia lingüística, originaria de la Etnometodología, y para la competencia ética. Tenemos qué celebrar en estos 50 años de la reglamentación de la profesión y del primer currículo nacional para los cursos de Psicología, sin embargo, en lo que dice respecto a la formación, tal vez no tanto como se querría. Palabras clave: Formación del psicólogo. Currículo. Enseñanza de Psicología. Diálogo. Competencia. Ensino Superior. 
Os diálogos e os debates sobre a formação em Psicologia atualmente estão candentes. Muitos cursos estão a pleno vapor tentando terminar a implantação ou avaliando seus currículos, conforme determinado pelas novas Diretrizes Curriculares, homologadas pelo Ministério da Educação, em 2004.

Nesses processos, muitas dúvidas e desafios surgiram e ainda surgem. É nesse sentido que pretendo dialogar sobre a formação em Psicologia atualmente no País, tentando ressignificar alguns conceitos constituintes das Diretrizes Curriculares dos cursos de Psicologia. Afinal, após 50 anos do primeiro currículo de abrangência nacional para os cursos de Psicologia, é importante fazer uma breve análise de onde chegamos. Não tenho a pretensão de realizar uma análise histórica, mas um recorte transversal de nossa formação nos dias de hoje.

Vale lembrar, as definições para os currículos atualmente não são mais sustentadas pelo chamado Curriculum Mínimo, e, sim, pelas Diretrizes Nacionais Curriculares.

O Curriculum Mínimo, que possui por base teorias da aprendizagem formais, constitui-se basicamente de processos institucionais de transmissão de conhecimentos e de inculcação de valores socialmente aceitos. Nesse processo, destacam-se: "uma metodologia genérica de ensino que se fundamenta na passagem de informações, um plano de ensino que se organiza em disciplinas isoladas e divididas simultaneamente (estrutura horizontal) e correlativamente (estrutura vertical)" (Rosi, 2005, p. 32). No currículo mínimo, a transmissão de conhecimentos se dá por meio do parcelamento de disciplinas, o estudo é isolado dos problemas e dos processos concretos do contexto social em que se dão, e, por fim, a aprendizagem é realizada por meio do acúmulo de informações.
Já as Diretrizes Curriculares constituem as orientações sobre princípios, fundamentos, condições de oferecimento e procedimentos para o planejamento, a implementação e a avaliação dos cursos envolvidos (Brasil, 2004). São dispositivos constituídos pela Lei de Diretrizes e Bases da Educação (1996) com o Edital n 04/1997, do Ministério da Educação, quando afirmam que as Diretrizes Curriculares Nacionais seriam definidas por cada curso superior no País, tomando por base a noção de perfis formativos e as competências e as habilidades necessárias para que tal perfil fosse contemplado.

Em outro momento (Bernardes, 2006), apresentei propostas de aproximações da formação em Psicologia com a saúde pública. Ali, problematizei os principais conceitos das Diretrizes Curriculares, argumentando o quão distante nossa formação estava da saúde pública. Não retomarei tais discussões, embora em um ou outro momento neste ensaio isso seja inevitável. Avanço aqui no sentido de apresentar propostas de ressignificação de alguns desses conceitos, o que não havia feito anteriormente, partindo de experiências compartilhadas por colegas e estudantes de alguns dos cursos de Psicologia do País, durante os últimos oito anos, póshomologação das Diretrizes Curriculares. Entretanto, estarei mais orientado para compartilhar dúvidas e apresentar alguns desafios do que para apresentar respostas prontas ou receitas pré-fabricadas em torno da reforma curricular.

Vale destacar que trabalho aqui sustentado por uma perspectiva pragmática na análise discursiva (Levinson, 1983), pela etnometodologia (Garfinkel, 1967; Coulon, 1987) e pela abordagem das práticas discursivas e da produção de sentidos (Spink, 1999). Dessa forma, o posicionamento é orientar o diálogo para os usos e os efeitos da linguagem, no caso, para os possíveis efeitos das Diretrizes Curriculares nos cursos. 
Neste ensaio sugiro a ressignificação de dois conceitos que considero importantes nas Diretrizes Curriculares da Psicologia: ênfases curriculares e competências e habilidades. Considero-as importantes mais pelos efeitos e ansiedades que estão produzindo nas comunidades acadêmicas que tenho contato que pelos conceitos em si. Para percorrer esse trajeto, organizei este texto da seguinte forma:

1. Sobre currículos, propostas políticopedagógicas e graduação.

2. Diretrizes Curriculares - alguns conceitos:

2.1. Ênfases curriculares;

2.2. Competências e habilidades;

3. Comemorações e alguns desafios.

\section{Sobre currículos, propostas político-pedagógicas e graduação}

São muitos os sentidos produzidos para currículo, para proposta político-pedagógica (PPC) e para graduação. Não há aqui intenção de apresentá-los. Pretende-se, tão somente, chamar a atenção para alguns efeitos e relacioná-los com alguns processos que vivenciamos em nosso cotidiano acadêmico atual.

Nesse sentido, a primeira questão é: boa parte dos processos de reformas curriculares são reduzidos a preocupações com conteúdos e disciplinas. Parece ainda predominar certa lógica territorial de que os conteúdos e as disciplinas delimitam poder das mais variadas formas, seja em instituições públicas, seja em instituições privadas.

A primeira questão, Portanto, esse primeiro desafio está vinculado à superação da ideia de que o currículo se reduz a uma lista ou à grade de disciplinas, mas, que é implementado no campo das relações de poder e na produção de cultura; mais que pensar sobre o currículo como reprodutor de algo, considerá-lo como efetivamente produzindo pessoas e coisas, modos de ser e de viver, produzindo modos de subjetivação (Veiga-Neto, 1995, 2003; Silva, 1993, 1995, 2001; Mancebo, 1997, 1999), ou, como diz Silva (2001, p. 15), um "currículo é sempre uma imposição de sentidos, de valores, de saberes, de subjetividades particulares".

Portanto, esse primeiro desafio está vinculado à superação da ideia de que o currículo não se reduz a uma lista ou à grade de disciplinas, mas é implementado no campo das relações de poder e na produção de cultura.

Uma segunda questão: em relatos de colegas e estudantes, percebo que não raro ocorre baixa participação da comunidade acadêmica nos processos de reformas curriculares. O desafio nas reformas é fazê-las transformarem-se em um processo de trabalho eminentemente coletivo, participativo e produtor de protagonismos e autorias. Isolar a comunidade acadêmica desse processo só provoca mais e mais afastamentos e movimentos excludentes. Incluo na comunidade acadêmica todos os atores que, de uma forma ou de outra, vivenciam ou fazem parte do curso (professores, estudantes, funcionários, preceptores, usuários dos serviços, etc).

Assim, ao início da reforma, talvez valha a pena conversar coletivamente com todos os envolvidos sobre alguns acordos que merecem ser constituídos:

a) Nível da reforma: caso a comunidade queira realizar uma reforma curricular, qual o nível de reforma que se quer atingir? Qual o grau de compromisso assumido pelo departamento/colegiado do curso, pelos professores, estudantes e funcionários?

b) Posicionamentos dos atores para a multiplicidade de sentidos da proposta político-pedagógica e da graduação: que vozes circulam na comunidade acadêmica sobre PPC, graduação, reformas? Que sentidos são produzidos a partir daí? Que perfil formativo será produzido? Que objetivos querem atingir? 
c) Relações com a comunidade acadêmica, a instituição e a sociedade: o que a PPC tem a ver com as comunidades envolvidas (acadêmica e não acadêmica), o curso e a estrutura organizacional/institucional? A PPC ajuda/facilita/dificulta tais relações? Qual é a história da instituição e do curso nesse contexto? Qual é a história da formação dos professores? Dos egressos? Qual é a história da região e o que se quer modificar nela? Que vozes constituem o curso? Enfim, qual é a vocação do curso?

São três conjuntos de questões importantes, além de outras, claro, para que não se perca o norte dos trabalhos das reformas. Não há intenção de buscar consenso entre os atores sobre tais questões, mas de clarear posicionamentos. De onde cada um dos envolvidos fala? Tais questões serão espécie de bússolas do exercício coletivo. Sem tais posicionamentos estarem minimamente claros, as reformas acabam se transformando em um exercício, boa parte das vezes, reduzido a trocas de título de disciplinas, que, no currículo anterior se chamavam Psicologia Clínica 1 e, após a reforma, Processos Clínicos.

Finalizando este primeiro tópico, destaco que currículo é vida, e, portanto, é desejável que esteja na pele das pessoas, encarnado em seus corpos, vivenciado e em constante processo de avaliação e mutação. Por ser vivo, o currículo que se estatiza, definha, iniciando processos de reproduções culturais, sociais, valores, poder e de práticas quase sempre questionáveis.

\section{Diretrizes Curriculares}

A construção das Diretrizes Curriculares marca um processo histórico importante para a Psicologia brasileira, pois foram produzidas a partir de debates, de relações de poder e de intensas negociações entre diversos atores/autores e instituições. Como todo processo histórico e coletivo, foi marcado por avanços e retrocessos. Apresentarei dois conceitos centrais nas Diretrizes Curriculares, procurando caracterizá-los e destacando a influência histórica de certas tecnologias em sua constituição. O termo tecnologias refere-se ao agenciamento de relações sociais e humanas, híbridos de conhecimentos, instrumentos, pessoas, sistemas de julgamentos, edificações e espaços, estruturados por uma racionalidade prática governada por metas mais ou menos conscientes (Rose, 1996, pp. 26-27).

Racionalidades práticas significam os modos ou sistemas de pensamento sobre a natureza da prática de governamento (quem pode governar, o que é governar, o que e quem é governado), capaz de tornar pensável e praticável alguma forma daquela atividade, tanto para aqueles que a exercem como para aqueles sobre quem é exercida.

As Diretrizes Curriculares, dessa forma, são dispositivos tecnológicos produzidos a partir de certa racionalidade prática, e caracterizam formas específicas de governo. Em tal dispositivo, abordaremos os conceitos de ênfases curriculares e de competências e habilidades, visto serem, em minha compreensão, centrais para a discussão das reformas curriculares.

Acredito que temos o que celebrar nestes 50 anos da regulamentação da profissão e do primeiro Currículo Nacional para os Cursos de Psicologia. No que diz respeito à formação, talvez não tanto quanto se gostaria. Entretanto, isso não impede de seguirmos adiante e de reelaborarmos conceitos que tendem a manter a situação como está.

\section{1. Ênfases curriculares}

O conceito de ênfases curriculares, conforme 
apresentado nas Diretrizes Curriculares da Psicologia, apresentados pelos artigos $10^{\circ} \mathrm{e}$ $12^{\circ}$ das Diretrizes (Brasil, 2004), está definido da seguinte forma:

Art. $10^{\circ}$. Pela diversidade de orientações teórico-metodológicas, práticas e contextos de inserção profissional, a formação em Psicologia diferencia-se em ênfases curriculares, entendidas como um conjunto delimitado e articulado de competências e habilidades que configuram oportunidades de concentração de estudos e estágios em algum domínio da Psicologia (grifos meus).

Dois aspectos destacam-se nesse artigo: o primeiro diz respeito a essa primeira definição de ênfases ("conjunto delimitado e articulado de competências e habilidades"). Em relação a essa primeira definição, deixarei para comentá-la junto ao próximo conceito, de competências e habilidades. A segunda definição caracteriza ênfases como "algum domínio da Psicologia". Claro, a pergunta salta aos olhos: mas, o que é um domínio da Psicologia? O artigo $12^{\circ}$ tenta responder: "Os domínios mais consolidados de atuação profissional do psicólogo no País podem constituir ponto de partida para a definição de ênfases curriculares (...)" (grifos meus).

Direto ao ponto: em que essa definição modifica ou promove avanços para as reformas curriculares na Psicologia? Os sentidos produzidos até o momento, em grande parte dos cursos de Psicologia pelo País, é o de replicar o que já existe. Domínios mais consolidados de atuação é o que já está aí: Psicologia Clínica, Psicologia Escolar, Psicologia Organizacional, assim, a área de conhecimento em Psicologia Escolar, por exemplo, aplicada fundamentalmente em campos vinculados a escolas (ou a algumas instituições de ensino e aprendizagem), vê-se diante de uma ênfase curricular em Psicologia e de processos educativos. Avançamos? Creio que seria nos iludirmos afirmar que sim. As reformas curriculares, para além de mudanças nas disciplinas, estão repletas de substituições de áreas de conhecimentos (ou campos de aplicação/atuação) para ênfases curriculares.

O parágrafo 3음o artigo 120 dá o tom para as mudanças: "As ênfases devem incorporar estágio supervisionado estruturado para garantir o desenvolvimento das competências específicas previstas" (grifos meus).

Antes das Diretrizes Curriculares, boa parte dos cursos de Psicologia organizavase nos três estágios tradicionais como obrigatórios: Psicologia Clínica, Psicologia Escolar e Psicologia do Trabalho - com suas especificidades e variações. Atualmente, boa parte desses cursos foi reduzida de três para dois estágios, pois vincularam os mesmos às ênfases, sob a condição de obrigatoriedade do curso de ofertar ao menos duas delas aos alunos. As ênfases, além de uma ou outra disciplina, foram reduzidas aos estágios.

Acredito que o ponto central dessa questão seja a expressão definidora de ênfases vinculada a caracterizá-las como os domínios consolidados da Psicologia, que são as áreas de conhecimento hegemônicas associadas diretamente aos campos de atuação que, historicamente, sustentam determinados modos do exercício profissional em Psicologia. Alguns autores (Bernardes, 2004; Mancebo, 1997, 1999; Jacó-Vilela, 1997) afirmam que, ao longo da consolidação do saber/ fazer psicológico, tais domínios sempre foram ditados pela Psicologia escolar, pela Psicologia organizacional e, posteriormente, pela Psicologia clínica:

As práticas e concepções da Psicologia aplicada, sob forte embasamento funcionalista, são praticamente ignoradas pela maioria dos autores de ensaios de história da Psicologia. A trajetória das práticas psicológicas na educação, no trabalho, e voltadas para o ajustamento do indivíduo em suas relações com os demais, 
consigo mesmo e no social, com pregnante desenvolvimento neste século, permanece por se fazer (Geniviève, 1992 como citado em Mancebo, 1999, p. 95)

É o modus operandi da Psicologia aplicada: a Psicologia aplicada à escola, à organização, à clínica etc. São saberes e técnicas racionais e científicas de controle individual e social, um exemplo das racionalidades práticas, conforme apresentado anteriormente, baseado no conceito de Nikolas Rose.

Assim, argumento que a noção de ênfases curriculares é herdeira de certa racionalidade prática, e produz nos processos das reformas curriculares a hegemonia histórica da Psicologia aplicada. Um dos motores desse processo é a não diferenciação entre áreas de conhecimento, campos de atuação e objetos de estudo, que se encontra consolidada nas escolas, empresas e clínicas (consultórios, ambulatórios, hospitais).

Áreas de conhecimento da Psicologia, campos de atuação e objetos de estudo são mesclados de forma a garantir a hegemonia da Psicologia aplicada. Trocando em miúdos, é o clássico discurso comumente escutado nos cursos de que a Psicologia escolar, por exemplo, é trabalhada em escolas e foca processos de ensino-aprendizagem, ou a Psicologia organizacional é trabalhada em empresas e foca seus estudos em processos e em relações de trabalho. Tudo o mais que compõe esses campos ou locais fica fora da atuação desse profissional, como se, nas escolas, não pudéssemos tratar de relações de trabalho, sofrimento, relações comunitárias, familiares, etc. Uma checagem rápida em instituições hospitalares, por exemplo, e verificamos claramente isso: os modos de atenção geralmente estão afastados dos modos de gestão. Os setores de recursos humanos possuem pouco ou nenhum diálogo com os setores clínicos e vice-versa.
Essa questão culmina, em meu modo de ver, na clássica discussão entre perfil generalista ou especializado na formação do psicólogo. Ora, percebo a existência de certo mito sobre a formação generalista em Psicologia. Nossa formação jamais foi generalista, ao contrário, sempre foi uma formação com dupla especialização precocemente estabelecida: a primeira especialização em determinado modus operandi centrado no indivíduo, individualizante e intimista, e uma segunda especialização em torno desse modus, localizada geralmente na atuação clínica. Em 1964, Angelini já demonstrava sua preocupação com o Curriculum Mínimo (Parecer no 403/62), que formava especialistas precocemente:

Diante da situação de fato criada pelo Parecer ( $n^{\circ} 403 / 62$ ), ou lutaremos para que o prazo seja dilatado, ou nos resignaremos a iniciar a especialização já no $4^{\circ}$ ano. Se essa última hipótese tiver de ser obedecida, estamos certos que a abreviação do curso se fará em detrimento de uma real formação (1964/1965, p. 45)

Em 1979, Botomé também problematizava a clássica divisão proposta na formação, derivada da chamada Psicologia aplicada. Diz ele:

As escolas de Psicologia ainda mantêm as clássicas divisões entre clínica, escola e indústria (serão essas as necessidades que o povo brasileiro tem em relação à Psicologia?). Essa e outras características de nossos cursos selecionam bastante os interesses e as percepções dos profissionais da Psicologia (1979, p. 11)

Segundo Mancebo, as instituições formadoras "têm atuado como reprodutoras de um modelo básico de atuação - as atividades clínicas desenvolvidas em consultórios particulares, na perspectiva de formação de profissionais liberais" (Mancebo, 1997, p. 23). Para Spink (1999), é a hegemonia do paradigma da simplificação, que opera por meio de processos de disjunção e 
redução. Fragmenta-se o saber/fazer em especialidades, com a ilusão de que cada especialidade aprofundará os conhecimentos em torno do objeto de estudo recortado e isolado (disjunção). Com o passar do tempo, serão associados e reduzidos a uma só teoria explicativa dos fenômenos (redução).

Dessa forma, ficam como desafios: como transcender a lógica replicante dessa racionalidade técnica (Psicologia aplicada)? Como transcender a lógica da dupla especialização? Como trazer para o debate a perspectiva do perfil generalista na formação?

Não sou pessimista. Argumento que a formação generalista não pode ser reduzida a um transitar, em pouco tempo, entre áreas ou campos de atuação em Psicologia; não pode ser confundida com a agregação da experiência dos estudantes por meio de um pot-pourri de diferentes áreas ou campos de atuação em Psicologia. Tampouco pode ser confundida com pluralidade ou diversidade (sugere-se sempre que os cursos sejam plurais em suas abordagens teóricas, garantindo, assim, a diversidade na formação).

Em outros momentos (Bernardes, 2004, 2006), argumentei que o conceito de ênfase pode ser caracterizado de maneira ampla, temática e de forma não excludente entre as escolhas realizadas pelo aluno das ofertas oferecidas pelo curso. Dessa forma, há alguma possibilidade de resistirmos às racionalidades práticas ditadas pela Psicologia aplicada e de produzirmos uma formação que esteja atenta às questões da vida, buscando transformações sociais e atendendo as necessidades das populações.

\subsection{Competências e habilidades}

Da mesma forma que o conceito de ênfase não abre para muitas celebrações nestes 50 anos de Psicologia, as noções de competências e habilidades também não. Afirmo que tais noções são herdeiras das noções de matérias e disciplinas do Curriculum Mínimo. Mas, nesse caso, também não sou pessimista. Há formas de ressignificar tais noções e de avançar nos processos de reformas curriculares.

Em outro momento, também argumentei que o repertório utilizado no debate sobre a formação em Psicologia se modificou ao longo dos tempos. A partir da década de 90, surgem novos termos que, a princípio, nada têm a ver com os anteriores, da década de 60: habilitações são substituídas por perfis de formação, currículo mínimo por Diretrizes Curriculares, campos de aplicação por ênfases curriculares, disciplinas por habilidades, e matérias por competências (Bernardes, 2004). Entretanto, os sentidos produzidos a partir dessas modificações praticamente permaneceram inalterados.

Competências e habilidades, junto ao conceito de perfil formativo, são os dois grandes conceitos que surgem no Edital n 04/1997, do Ministério da Educação, orientadores das Diretrizes Curriculares, ou seja, são centrais para as reformas curriculares.

As competências e as habilidades são definidas nas Diretrizes Curriculares da Psicologia da seguinte forma:

Art. 40 - A formação em Psicologia tem por objetivos gerais dotar o profissional dos conhecimentos requeridos para o exercício das seguintes competências e habilidades gerais: (...)

Art. $8^{\circ}$ - As competências reportam-se a desempenhos e atuações requeridas do formado em Psicologia, e devem garantir ao profissional um domínio básico de conhecimentos psicológicos e a capacidade de utilizá-los em diferentes contextos que demandam a investigação, análise, avaliação, prevenção e atuação em processos psicológicos e psicossociais, e na promoção da qualidade de vida. (...) 
Art. 9o - As competências, básicas, devem apoiar-se nas habilidades de: (...)

Art. 14 - A organização do curso de Psicologia deve, de forma articulada, garantir o desenvolvimento das competências do núcleo comum, seguido das competências das partes diversificadas - ênfases - sem concebê-los, entretanto, como momentos estanques do processo de formação (Brasil, 2004, grifos meus).

A fundamentação das novas diretrizes curriculares no ensino superior, ditadas pela Lei de Diretrizes e Bases da Educação (LDB), de 1996, sustenta-se em concepções relacionadas às pedagogias psicológicas, principalmente as concepções derivadas das obras de Perrenoud $(2001,2002)$ e Thurler (2001), que centram o processo de aprendizagem na questão das competências e das habilidades.

Machado (2002), um dos defensores da pedagogia psicológica, ao definir competências, afirma que são padrões de articulação do conhecimento a serviço da inteligência. São associadas aos esquemas de ação - desde os mais simples até as formas mais elaboradas de mobilização do conhecimento -, às capacidades, "como a capacidade de expressão nas diversas linguagens, a capacidade de argumentação na defesa de um ponto de vista, a capacidade de tomar decisões, de enfrentar situaçõesproblema, de pensar sobre e de elaborar propostas de intervenção na realidade" ( $p$. 146).

Para Allessandrini, as competências são definidas pela "capacidade de compreender uma determinada situação e reagir adequadamente a ela" (2002, p. 164). É a qualidade de quem é capaz de apreciar e de resolver certo assunto, um ato em torno de determinado objeto. Relaciona-se ao saber fazer algo, que, por sua vez, envolve uma série de habilidades. É uma posse, uma característica do indivíduo, sempre da ordem do indivíduo. Vale destacar que, segundo as Diretrizes, competências e habilidades reportam a "desempenhos e atuações requeridas do formando".

Nesse processo, no que concerne à concepção de conhecimento e cultura subjacente às diferentes políticas curriculares oficiais, percebe-se uma visão utilitarista e instrumental de currículo, limitadora das potencialidades humanas. A organização do currículo por competências faz-se traçando objetivos e definindo operações cognitivas (Pacheco, 2001). O conhecimento e a cultura não são problematizados como campo plural de conflitos e acordos, e a função cultural da universidade é submetida à lógica mercantil da formação para habilidades e competências (Chassot, 1998); trata-se, portanto, de conceito com raízes cognitivas e indivíduocentrado, que localiza as competências para as habilidades no corpo/psiquismo do indivíduo.

A modificação do repertório ao longo dos anos, anteriormente apresentada, aponta uma mudança nas concepções de aprendizagem: da concepção ambientalista, eminentemente behaviorista, em que os conteúdos são o centro do processo, para os processos cognitivos centrados no estudante (competências e habilidades), de concepção externalista para uma concepção internalista, da ordem do ambiente e do conteúdo para a cognição e os processamentos de informação localizados no aluno, que é o responsável pelas competências e habilidades adquiridas ou, também, o responsável pela não aquisição das mesmas.

ssa concepção de competências e habilidades localizadas no indivíduo também explicita formas de racionalidade prática analisadas por Rose (1996). Segundo Pacheco, 
A pedagogia por competências decorre do modelo de gestão científica do currículo, tornando-se, por isso, um instrumento que reforça não só a racionalidade técnica mas também as práticas pedagógicas que delimitam o processo ensino/aprendizagem como um dispositivo que é justificado pela transmissão (2001)

Em outro momento (Bernardes, 2004), argumentei que essa lógica está associada a uma perspectiva neoliberal de educação, preocupada com objetivos e metas. Pacheco afirma que:

Objectivo e competência estão ligados a critérios de ordenação do conhecimento segundo um código burocrático e disciplinar, mesmo que a imagem dominante nos discursos dos reformadores seja a da transdisciplinaridade. Voltando à definição de competência e objectivo, diremos que são instrumentos de uma racionalidade curricular técnica que têm por função compendiar o conhecimento em comportamentos ou em saberes ligados à acção (2001)

As diretrizes curriculares atuais fazem parte da herança da tendência liberal tecnicista, orientada para a cientificidade e a competência e para as técnicas e os métodos que aumentam a eficiência da aprendizagem. Oliveira (1999) afirma que o que resta ao psicólogo, nessa tendência de ensino, é conhecer e dominar a tecnologia educacional e os procedimentos instrucionais.

Diante dessas questões, também não sou pessimista. O desafio é, portanto, como ressignificar o conceito de competência? Como trabalhar, por exemplo, o conceito de competência sob outras perspectivas que não reduzindo-o às perspectivas individualistas ou cognitivistas? Objetivando iniciar um debate sobre essa questão, apresento dois exemplos dessa possibilidade:

\section{1) Competência linguística}

Em geral, as teorias linguísticas centradas na análise da gramática formalizada denominam competência linguística o conjunto de conhecimentos que permitem ao falante de uma língua compreender e produzir certa quantidade, potencialmente infinita, de orações gramaticalmente corretas, com uma quantidade finita de elementos, ou, também, que tais processos são centrados nos conhecimentos que o falante possui. Chomsky, linguista norte-americano, é um exemplo de pensador dessa perspectiva.

Para Gardner, a competência linguística está centrada em processo psicológico vinculado às capacidades intelectuais (fonologia e sintática são centrais na inteligência, a semântica, com a inteligência lógico-matemática, e a pragmática, com a inteligência interpessoal).

Algumas concepções cognitivas definem competência linguística como aquela capacidade que possui a mente humana de processar informações a partir de um sistema de símbolos.

Em outras palavras, as concepções acima apresentadas argumentam que a competência linguística se centra em torno de operações gramaticais interiorizadas no indivíduo que se articulam e se desenvolvem de acordo com sua capacidade de falar. Essa competência origina-se no próprio indivíduo, e não no campo do coletivo ou das relações entre as pessoas. Assim, a competência linguística se faz realidade através de regras generativas que se relacionam com a gramática, que é saber organizar-se e estruturar-se.

Proponho considerar competência linguística tomando por base não as concepções cognitivas, mas sim, a vertente pragmática da Linguística e os aportes teóricos da etnometodologia.

A pragmática é o estudo dos princípios que regulam os usos da linguagem (Iñiguez, 2002). A partir da pragmática, realizamos a análise da produção de sentidos: os usos e os efeitos 
da linguagem; a pragmática, dessa forma, estabelece como foco o estudo da linguagem em uso e concentra-se no que acontece quando as pessoas falam. É no contexto da produção linguística que está a compreensão de seu significado.

A pragmática analisa práticas sociais concretas, focando na significação linguística de acordo com a interação existente entre quem fala e quem ouve, do contexto da fala, dos elementos socioculturais em uso e, também, dos objetivos, efeitos e consequências desse uso.

Já a etnometodologia possui como um dos princípios a ideia de membro competente. Esse conceito não está relacionado à ideia de pertencer a um grupo - alguém fazer parte de um grupo. Essa é uma parte da noção de competência, mas não a única:

A ideia de competência não é unicamente estar socializado em um grupo social, mas dispor dos recursos, ou seja, das competências para a ação conjunta e a interação. Ser capaz de interagir com outras pessoas. A mais importante de todas as competências é a lingüística; se não conhecemos um idioma, não podemos ser competentes nele. (...) A questão não está apenas, insisto, em socializar-se em um grupo, mas em ser capaz de falar, o que é algo muito diferente. (...) A competência, no sentido da etnometodologia, é, sobretudo, o manejo da linguagem comum (Iñiguez, 2002, pp. 165-166)

Vale destacar, linguagem, nessa perspectiva, não se reduz a funções ou a processos básicos ou mentais. A linguagem aqui é compreendida como um fenômeno eminentemente coletivo. Para pragmatistas e etnometodólogos, a linguagem não existe no interior da cabeça das pessoas, ela existe no mundo cotidiano. É mais uma forma de construção do mundo e de nós mesmos que de suas descrições. A linguagem, então, é uma forma de ação social, mais que um espelho ou um reflexo dos acontecimentos.
Dessa maneira, como em nossos currículos e na formação em Psicologia são trabalhadas questões vinculadas à competência linguística? Abaixo, apresento dois exemplos: um primeiro, vinculado à noção de campo na pesquisa, e um segundo, relacionado à prática profissional.

Pesquisa: nessa perspectiva, na pesquisa social, por exemplo, o campo de pesquisa não é algo dado, pré-existente, com existência independente do pesquisador(a). Peter Spink (2003) nos auxilia aqui com a noção de que o campo (de pesquisa) se constitui desde o primeiro momento que o pesquisador(a) fala dele. A todo instante, quem investiga está em campo; é o que o autor chama de campo-tema.

Mesmo em sentido clássico, o pesquisador, quando chega ao campo a ser pesquisado,

está diante de uma comunidade que não conhece, e determinados problemas the serão colocados. Então vai compartilhar um universo de significados, uma certa experiência etc. (...) Se você não for membro competente de um grupo, será muito difícil interagir adequadamente, e parece ser pouco possível, ou altamente improvável, fazer-se membro competente de um grupo que não seja o próprio (Iñiguez, 2002, p. 139)

Prática profissional: já na prática profissional, a noção de setting ou de contexto depende das formas linguísticas que usamos para configurar a interanimação dialógica. Costumamos considerar a noção de contexto como um cenário que acolhe determinada cena de um indivíduo ou entre pessoas. O que proponho é pensar que esse cenário é produzido a partir das interanimações dialógicas oriundas da linguagem em uso. É nos usos e nos efeitos das palavras que configuramos o que venham a ser as relações. O contexto não é algo imutável, fixo, pré-existente à vida das pessoas. Ele é produzido nas relações que constituímos com nossos usuários, pacientes, clientes. $\mathrm{O}$ uso dessas palavras não é arbitrário: cada 
uma delas remete a uma relação distinta da outra. A palavra usuário, no campo da Psicologia, e, mais especificamente, no campo da saúde, remete-nos a um contexto quase que imediatamente associado à saúde pública, a palavra cliente, a uma determinada concepção teórica em Psicologia, a palavra paciente, a toda uma determinação histórica do poder biomédico sobre as concepções de saúde e doença. Enfim, a competência linguística tem a ver com o domínio desses códigos em determinada interação, atentando para seus usos e efeitos.

Em suma, a competência linguística está centrada nas condições da dialogia, compreendida aqui como uma prática social e em seu potencial de produção da realidade (mais que descritivo), que possui as seguintes características: polifonia (multiplicidade de vozes) e polissemia (multiplicidade de sentidos), uso não abusivo das relações de poder, marcadas pela horizontalidade nas relações, implicando, portanto, o abandono de posicionamentos hierarquizantes, da neutralidade e de metalinguagens na produção da ciência, e, finalmente, caracterizado pelo fato de o conhecimento não estar na mente de um indivíduo, mas nas relações entre as pessoas, resgatando, assim, a raiz da palavra diálogo (dia - entre; logos - conhecimento): o conhecimento que é produzido entre as pessoas.

\section{2) Competência ética - ética dialógica}

Para avançarmos na ressignificação de competências e não reduzirmos seu conceito a um conjunto de habilidades do indivíduo, proponho refletirmos sobre a competência ética. Esta propõe não reduzirmos o conhecimento e suas aplicações a um saber/ fazer, mas em como saber/fazer e para que saber/fazer.
Além da ética prescritiva, observada nos manuais de pesquisa e códigos profissionais, propomos o debate sobre a ética dialógica (Spink, 2000) e a noção de competência ética (Varela, 2003). Para Varela, o comportamento ético não surge de hábitos ou da obediência a padrões ou a regras. A vida cotidiana, ou o micromundo (jamais considerado oposição a macromundo), é repleta de confrontações imediatas que exigem comportamentos éticos, ações concretas, personificadas, corporificadas, vivas. A questão central para o diálogo é como, no micromundo, compreender/estabelecer relações éticas no campo profissional (seja na pesquisa, seja na prática profissional).

Já para Spink, a ética dialógica vai além da ética prescrita, normativa, dos códigos deontológicos e documentos oficiais. A autora (2000) argumenta a favor da ética da responsabilidade, e, para isso, apresenta a ética dialógica (pautada na competência ética de Varela) em distinção à ética prescritiva (pautada na moral contratual).

A dialogia é o conceito central para a construção da noção de ética dialógica. Para conceituar dialogia, partimos do pressuposto que dar sentido ao mundo é o mais poderoso motor da ação humana:

Estamos também propondo que a produção de sentido está colada ao uso da linguagem, e que a linguagem em uso é um fenômeno da ordem da interação. Dito de outra forma, a produção de sentido é um fenômeno sociolinguístico: os sentidos são construídos quando uma ou mais vozes se confrontam, quando a voz de um ouvinte responde à voz de um falante (speaker) (Spink, 2000, p. 19)

Novamente, dois exemplos, um, na pesquisa, e outro, na prática profissional: no exercício da pesquisa, a ética dialógica (pautada na competência ética de todos os envolvidos nos processos), leva os preceitos éticos de plena informação, livre consentimento e análise de 
riscos e benefícios às últimas consequências. São três os cuidados éticos essenciais nessa perspectiva: "os consentimentos informados, a proteção do anonimato e o resguardo do uso abusivo do poder na relação entre pesquisador e participantes" (Spink, 2000, p. 20).

Já no exercício da prática profissional, é pensar a ética dialógica a partir dos posicionamentos da dialogia (polifonia, polissemia, relações de poder), ser produzido entre as pessoas.

A competência ética se caracteriza pelo contexto concreto em que os sujeitos estão inseridos e se sentem pertencentes e o que é produzido a partir daí. Mais que isso, é também caracterizada pela vivência de tal conceito em seu cotidiano. Varela apresenta o conceito de enação para caracterizar a corporificação/encarnação da competência ética que busca a habilidade para atender, expandir essa atenção e concentrar-se em objetos concretos da vida cotidiana.

Além de trabalhar com os estudantes questões deontológicas ou da moral contratual, é fundamental trabalhar o diálogo, o encontro e a alteridade. Tenho certa sensação de que nossas PPC estão aquém dessas possibilidades, mas ficam os desafios.

\section{Comemorações e alguns desafios...}

Muito há o que comemorar nestes 50 anos! E muito mais comemoraremos no avanço aos desafios em busca de caminhos progressistas e críticos para o diálogo sobre formação em Psicologia. Assim, valem as indagações e as dúvidas abaixo, dentre outras:

Que sentidos são produzidos pela e para a lógica disciplinar/conteudista ou, mais atualmente, pela lógica das competências e habilidades nas Diretrizes Curriculares
Nacionais?

Estamos dispostos a manter a articulação entre as distintas áreas de conhecimento e os campos de atuação em Psicologia? Que rupturas seriam necessárias em nosso cotidiano? Que territórios ou espaços de poder seriam modificados?

Que modificações nas práticas profissionais seriam realizadas para que isso fosse possível? E na formação? A graduação seria a mesma como a constituímos atualmente?

O curso é constituído por quais vocações? Vocações no sentido forte de vozes multivocalidade/polifonia e polissemias.

Que dispositivos construímos em nosso cotidiano para dar conta dessas questões?

Que diálogos são possíveis e desejáveis?

Alguns pequenos passos/desafios nos processos de reformas curriculares são importantes na tentativa de esboçar respostas a algumas das indagações acima:

O exercício do diálogo no sentido de explicitação dos sentidos e posicionamentos produzidos por diferentes atores sociais. Não falamos a mesma língua, e os conceitos/ palavras não possuem sentido único e homogêneo. Isso não é um problema (sinto que é o contrário, é onde reside nossa força como vasto campo de saber/fazer). Não se busca homogeneizar tais diferenças por meio de processos consensuais, boa parte das vezes artificiais. O principal é o que fazer com essas divergências/diversidades/diferenças:

Diálogos com todos os envolvidos no processo de formação, promovendo desnaturalizações nas relações entre os grupos envolvidos (atores e posicionamentos distintos). Os processos de produção de currículo exigem 
participação e convite permanente a todos os envolvidos, sejam professores, alunos, preceptores, supervisores locais, comunidade envolvida, etc;

Diálogos sobre as relações de poder que circulam/são produzidas entre os distintos grupos e instituições, explicitando os diferentes posicionamentos dos atores envolvidos;

Diálogos sobre nossas estruturas e práticas institucionais e as concepções de formação que circulam/são produzidas a partir daí. O fato de a organização dos cursos, por exemplo, ser baseada em um somatório de departamentos pode conferir determinada configuração aos mesmos, distinta da instituição de ensino que não opera sob a égide departamental.

Enfim, fica o convite à produção de novos sentidos a alguns conceitos e ideias que persistem em permanecer inalterados entre nós, novos sentidos que possam ser oriundos da história do curso e da região, os saberes e fazeres locais, orientados para as necessidades de nossas populações. Daí o convite a dar novo sentido às competências linguísticas, que falam de contextos específicos de cada um dos cursos, e às competências éticas, que falam de nossas condições de dialogia. 


\section{Jefferson de Souza Bernardes}

Universidade Federal de Alagoas - Doutor em Psicologia Social

E-mail: jbernardes.ufal@gmail.com

\section{Endereço para envio de correspondência:}

Campus A. C. Simões / Curso de Psicologia - ICHCA - Av. Lourival Melo Mota, s/n, Cidade Universitária Maceió - AL, CEP: 57072-900. 


\section{Referências}

Allessandrini, C. D. (2002). O desenvolvimento de competências e a participação pessoal na construção de um novo modelo educacional. In P. Perrenoud, M. G. Thurler \& L. Macedo et al. As competências para ensinar no século XXI - a formação dos professores e o desafio da avaliação. Porto Alegre: Artmed Editora.

Angelini, A. L. (1964/1965). O status do psicólogo em diversos países: excerto da Conferência Internacional sobre Intercâmbio em Psicologia. Boletim de Psicologia, 16/17 (47-50), 3-40.

Bernardes, J. S. (2006). Formação generalista em psicologia e sistema único de saúde. In I Fórum Nacional de Psicologia e Saúde Pública: contribuições técnicas e políticas para avançar o SUS. Brasília, DF: Conselho Federal de Psicologia.

Bernardes, J. S. (2004). O debate atual sobre a formação em psicologia no Brasil -permanências, rupturas e cooptações nas políticas educacionais. Tese de doutorado. Programa de Estudos Pós-graduados em Psicologia Social. PUC-SP São Paulo.

Botomé, S. P. (1979). A quem nós, psicólogos, servimos de fato? Psicologia, 5(1), 1-15.

Brasil. (1997). Edital $n^{\circ}$ 04/1997. Brasília, DF: Ministério da Educação.

Brasil. (1996). Lei no 9.394, de 20 de dezembro de 1996. Lei de Diretrizes e Bases da Educação (LDB). Brasília, DF: Ministério da Educacão.

Brasil. (2004). Resolução CNE/CES Nº 8, de 7 de maio de 2004. Diretrizes Curriculares para os cursos de Psicologia. Brasília, DF: Conselho Nacional de Educação.

Chassot, A. (1998). Currículo: (re)montando fragmentos. Seminário Currículos. São Leopoldo, Universidade do Vale do Rio dos Sinos, 25/09/1998. (mimeo).

Coulon, A. (1987). La etnometodología. Madrid: Cátedra.

Garfinkel, H. (1967). Studies in etnomethodology. England Cliffs: Prentice Hall.

Iñiguez, L. (2002). A análise do discurso. In J. B. Martins, N. D. E. Hammouti, L. Iñiguez, Temas em análise institucional e em construcionismo social. São Carlos, SP: Fundação Araucária.

Jacó-Vilela, A. M. (1999, jul./dez.). Formação do psicólogo: um pouco de história. Interações: Estudos e Pesquisas em Psicologia, 8(4, Supl.), 79-91.

Levinson, S. C. (1983). Pragmatics. Cambridge: Cambridge University Press.

Machado, N. J. (2002). Sobre a ideia de competência. In P. Perrenoud, M. G. Thurler, L. Macedo et al. As competências para ensinar no século XXI - a formação dos professores e o desafio da avaliação. Porto Alegre: Artmed Editora.

Mancebo, D. (1997). Formação do psicólogo: uma breve analise dos modelos de intervenção. Psicologia: Ciência e Profissão, 1(17), 20-28.

Mancebo, D. (1999). Formação em psicologia: gênese e primeiros desenvolvimentos. In A. M. Jacó-Vilela, F. Jabur \& H. B. C. Rodrigues (Orgs.), Clio-Psyché: Histórias da psicologia no Brasil. (pp. 93-120). Rio de Janeiro: UERJ, NAPE.

Oliveira, E. S. G. (1999). Psicologia e tendências pedagógicas no Brasil - perfis de atuação do psicólogo. In A. M. Jacó-Vilela,
F. Jabur \& H. B. C. Rodrigues (Orgs.), Clio-Psyché: histórias da psicologia no Brasil (pp. 209-213). Rio de Janeiro: UERJ, NAPE.

Pacheco, J. A. (2001). Competências curriculares: as práticas ocultas nos discursos das reformas. In 24 Reunião da ANPED. Recuperado em 04 novembro, 2010 de http://www.anped. org.br/reunioes/24/ts2.doc.

Perrenoud, P. et al. (2001). Formando professores profissionais. Quais estratégias? Quais competências? Porto Alegre: Artmed.

Perrenoud, P., Thurler, M. G., \& Macedo, L. et al. (2002). As competências para ensinar no século XXI - a formação dos professores e o desafio da avaliação. Porto Alegre: Artmed Editora.

Rose, N. (1996). Inventing our selves: Psychology, power and personhood. Cambridge: Cambridge University Press.

Rosi, S. S. et al. (Orgs.). (2005). Projeto multiplica SUS. Oficinas de capacitação pedagógica para a formação de multiplicadores. Brasília, DF: Ministério da Saúde

Silva, T. T. (1993). Desconstruindo o construtivismo pedagógico. Educação e Realidade. Educação \& Realidade Edições, 18(2), 3-10.

Silva, T. T., \& Moreira, A. F. B. (1995). Territórios contestados. Petrópolis, RJ: Vozes.

Silva, T. T. (2001). Dr. Nietzsche, curriculista - com uma pequena ajuda do professor Deleuze. In 24 Reunião da ANPED. Recuperado em 04 novembro, 2010 de http://www.anped. org.br/reunioes/24/T1299570907599.doc.

Spink, M. J. (Org.). (1999). Práticas discursivas e produção de sentidos no cotidiano-aproximações teóricas e metodológicas. São Paulo: Cortez

Spink, M. J. (2000, jan./jun.). A ética na pesquisa social: da perspectiva prescritiva à interanimação dialógica. Psico, 1(31), 7-22.

Spink, P. K. (2003). Pesquisa de campo em psicologia social: uma perspectiva pós-construcionista. Psicologia \& Sociedade, 15(2), 18-42. Recuperado em 18 junho, 2012 de http://www. scielo.br/scielo.php?script =sci_arttext\&pid=S010271822003000200003\&lng=en\&tlng=pt.

Thurler, M. G. (2001). Inovar no interior da escola. Porto Alegre: Artmed.

Varela, F. (2003). La habilidad ética. Barcelona: Agencia Literária Eulama.

Veiga-Neto, A. (2003). Foucault e a educação. Belo Horizonte, MG: Autêntica.

Veiga-Neto, A. (1995). Currículo e cultura. Trabalho apresentado no curso de extensão Teoria e Prática da Avaliação Escolar, promovido pela UFRGS, para o Conselho de Diretores das Escolas Agrotécnicas Federais, na EAF de Sertão, RS. Recuperado em em 18 de junho de 2011 de http://orion. ufrgs.br/faced/alfredo/sertao.htm 